\section{NASA bids are not a popularity contest}

You recently conducted an online popularity poll of three proposals competing for selection as the next NASA Discovery Program mission (Nature http://doi. org/h79; 2012). In my view, the concept and execution of this poll demeans Nature and belittles what is at stake.

Worse, there are indications that the poll could have been manipulated. Voting for one particular mission occurred in a large burst on a single day. It is immaterial whether this was caused by the mission teams enlisting many supporters to vote quickly, or by people who worked out an easy way to vote multiple times. The point is that the results are not meaningful.

Popularity contests are not the way to choose among scientific alternatives. Although public interest needs to be taken into account when spending taxpayers' money, selecting a mission should ultimately depend on its scientific merit and technical feasibility.

NASA's missions have a track record of exciting the public anyway, with web hits for different missions leading to server saturation during key events. The likely effectiveness of each mission's outreach programme needs to be evaluated by looking carefully at the large, detailed proposals submitted by each mission team. Michael F. A'Hearn University Park, Maryland, USA. mahearn@mac.com Competing interests declared; see go.nature.com/1qferq.

\section{Tourism ban won't help Indian tigers}

The Indian Supreme Court's temporary injunction against tourism in core areas of tiger reserves could place the animals at greater risk of poaching if it becomes permanent, by reducing revenue for park management
(Nature 488, 10; 2012). The

injunction has now been extended until 27 September.

Most of the reserves with the highest numbers of tigers and tourists are in the state of Madhya Pradesh. In 2010-11, the state's 35 parks received US $\$ 17.1$ million from government sources. Five tiger reserves generated most of the $\$ 2.8$ million obtained from tourism. In 2011-12, Bandhavgarh reserve received $\$ 1.2$ million in tourist revenue and almost the same amount from government sources. Tourism therefore yields $25-50 \%$ of tiger conservation funds in Madhya Pradesh, safeguarding up to 130 tigers.

Different management strategies would be more effective in overcoming conservation concerns stemming from disruptive tourist behaviour. Ralf C. Buckley Griffith University, Australia. r.buckley@griffith.edu.au H. S. Pabla Madhya Pradesh, India.

\section{Tighten up Japan's stem-cell practices}

Japan has bioethical regulations and clinical guidelines in place for experimental stem-cell therapies and for stem-cell-based pharmaceuticals. As a forensic pathologist who has worked on a patient who died after mesenchymal stem-cell therapy in Japan, I am aware that other patients receiving this treatment have developed serious and even fatal complications. These cases indicate that Japan's regulatory infrastructure needs to be more strongly enforced.

Reaction in Japan to these cases has been minimal. This contrasts with the tough approach of the US Food and Drug Administration, which led to the prompt prosecution of clinicians and companies involved in similar cases in Colorado and Texas (see Nature 477, 377-378; 2011).

Japan's Investigative
Commission for Institutional Framework in Regenerative Medicine recommended establishing a punitive system for physicians and clinics practising unethical activities, but its 2011 report made no mention of such plans. The country's specialist medical organizations should push for government collaboration if an effective disciplinary system is to be established (E. Dolgin Nature Med. 16, 495; 2010).

The Japanese Medical Ethics Committee, for example, needs to work more like the UK General Medical Council, which does not depend on the country's judiciary system to exercise its powers.

The Japanese Society for Regenerative Medicine and the International Society for Stem Cell Research should collaborate with Japan's health ministry to establish a system to prevent further stem-cell-related deaths. Hiroshi Ikegaya Kyoto Prefectural University of Medicine, Kyoto, Japan. ikegaya@koto.kpu-m.ac.jp

\section{Avoid constructing wind farms on peat}

Scotland's government is planning to build large-scale wind farms to reduce carbon emissions from electricity production, some of which could be situated on peatlands. We contend that wind farms on peatlands will probably not reduce emissions, unlike those on mineral soils.

Wind farms are often located in upland areas because most of these are windy, distant from residential areas and of low agricultural value. Peatlands are prevalent in UK uplands and are richer in carbon than mineral soils because peats are formed from decomposing wet vegetable matter. Peatlands therefore have a higher net carbon loss when drained for construction.

The UK wind industry uses a method we and our colleagues developed to estimate carbon emissions (D. R. Nayak et al. Mires Peat 4, 9; 2010). On this basis, and assuming current emission factors for electricity generation, our previous work argued that most peatland sites could save on net emissions if peat is not drained and if sites are restored after construction.

However, emissions factors are likely to drop significantly in the future owing to reduced fossilfuel use in electricity generation (see go.nature.com/lnowou). As a result, peatland sites would be less likely to generate a reduction in carbon emissions, even with careful management. Unless the volume of peat excavated can be significantly reduced relative to energy output, we suggest that construction of wind farms on non-degraded peats should always be avoided.

Jo Smith, Dali Rani Nayak, Pete Smith University of Aberdeen, UK. jo.smith@abdn.ac.uk

\section{Improve sanitation on India's railways}

A good place to start with India's problems of poor sanitation (see, for example, Nature 486, 185; 2012) would be the country's 150-year-old railway network, which carries 30 million passengers every day. Hygienic sanitation technologies have yet to be installed in all passenger coaches.

The basic lavatory design throws excreta on to the open railway tracks. This system risks spreading pathogens and parasites to distant locations.

One solution would be to install small biogas plants on trains or at stations. These would generate revenue - from excreta - that could be used to employ cleaning and disposal squads. Abhishek Sharma, M. K. Unnikrishnan Manipal University, Karnataka, India. abhisheksharma0991@gmail.com Ankush Madaan McGill University, Montreal, Quebec, Canada. 


\section{Scientific genius: in different guises}

Dean Keith Simonton's contention that scientific genius is extinct (Nature 493, 602; 2013) may itself be based on an extinct - or at least dying - concept of genius.

In the past, geniuses were lone scientists who distilled extant knowledge to spawn innovation. Simonton lays part of the blame for their extinction on modern team science (see K. Börner et al. Sci. Transl. Med. 2, 49cm24; 2010). But a different kind of genius can exist inside a team. An example might be the member who instinctively optimizes the group's complementary expertise to elicit a ground-breaking discovery.

Even more radical forms of genius are conceivable. The hallmark combination of knowledge and process can create a form of collective genius (A. W. Woolley et al. Science 330, $686-688 ; 2010)$. And as scientists become more connected with each other and technology, genius could emerge from a hybrid of human and machine intelligence.

There is no need to bemoan the demise of the lone genius. Rather, we should be fostering and studying more contemporary forms of scientific genius.

Stephen M. Fiore University of Central Florida, Orlando, Florida, USA.

sfiore@ist.ucf.edu

\section{Scientific genius: will continue to thrive}

Dean Keith Simonton's contention that scientific genius is extinct (Nature 493, 602; 2013) invites comparison with Lord Kelvin's famous speech to the British Association for the Advancement of Science in 1900, in which he remarked, "There is nothing new to be discovered in physics now. All that remains is more and more precise measurement." The discoveries of quantum mechanics and relativity soon made nonsense of this hubristic claim.

Simonton suggests that these were the last new fields, and that disciplines founded since are simply hybrids of existing ones. But science does not proceed in the way followed by the journalist in Charles Dickens's The Pickwick Papers (1836), who, when asked to write on Chinese metaphysics, combined the information he read "for metaphysics under the letter $\mathrm{M}$, and for China under the letter C" from the Encyclopaedia Britannica.

Information theory, for example, founded by Claude Shannon in 1948, is surely a field in its own right — albeit with applications to many different fields. Other emergent fields include network theory and the science of complex systems, which are providing insight into systems from organisms to societies and ecosystems. Opportunities for scientific genius and surprising discoveries are nowhere near exhausted.

Len Fisher University of Bristol, Bristol, UK.

len.fisher@bristol.ac.uk

\section{Don't belittle the rebound effect}

We disagree with Kenneth Gillingham and colleagues' contention that the rebound effect - in which greater consumption offsets the energy saved by increasing efficiency - is exaggerated (Nature 493, 475-476; 2013). We and others have shown rebound effects as large as 60\% (see, for example, M. Frondel et al. Energy Econ. 34, 461-467; 2012).

In our view, energy-efficiency standards are among the least cost-effective ways of lowering carbon emissions (see H. Allcott Am. Econ. Rev. 101, 98-104; 2011). For example, the costs of the US Corporate Average Fuel Economy standard are more than ten times higher than a petroleum tax that induces the same reduction in oil consumption (R. W. Crandall J. Econ. Persp. 6, $171-180 ; 1992)$. This is mainly because of the rebound effect: the standard actually encourages driving by marginally lowering its cost, unlike a tax.

The greater cost-effectiveness of a tax could be undermined by coupling it with an efficiency standard, as Gillingham et al. suggest, because of interaction effects between the two.

Manuel Frondel, Colin Vance Rhineland-Westphalia Institute for Economic Research, Essen, Germany.

vance@rwi-essen.de

\section{Guarding children's genetic privacy}

Your coverage of genetic privacy issues (Nature 493, 451 and Nature 494, 7; 2013) does not address concerns relating to DNA collected from children, who have contributed thousands of biobank samples worldwide.

Open sharing of genotype and phenotype information is crucial for advancing research into childhood diseases, but depends on consent from patients or their parents. Children cannot themselves consent to participation in research with long-term privacy implications. However, parental consent is currently founded on unrealistic promises of anonymity and confidentiality.

For the responsible conduct of research, parents need to be made fully aware of the risk of identifiability before granting consent on their children's behalf (J. E. Lunshof et al. Nature Rev. Genet. 9, 406-411; 2008).

Stringent research protocols are necessary to protect child donors (D. Gurwitz et al. Science 325, 818-819; 2009). But we should not prohibit the publication of sequencing information that could save lives. For example, mutations in calmodulin gene sequences are associated with some sudden infant deaths (L. Crotti et al. Circulation http:// doi.org/kjz; 2013). Jeantine E. Lunshof Harvard Medical School, Boston, Massachusetts, USA. jelunshof@genetics.med.harvard. edu

David Gurwitz Tel Aviv

University, Israel.

\section{'Antifragility' as a mathematical idea}

In his review of my book Antifragile, Michael Shermer mischaracterizes the concept of 'antifragility' (Nature 491, 523; 2012).

'Fragility' can be defined as an accelerating sensitivity to a harmful stressor: this response plots as a concave curve and mathematically culminates in more harm than benefit from random events. 'Antifragility' is the opposite, producing a convex response that leads to more benefit than harm.

We do not need to know the history and statistics of an item to measure its fragility or antifragility, or to be able to predict rare and random ('black swan') events. All we need is to be able to assess whether the item is accelerating towards harm or benefit. The relation of fragility, convexity and sensitivity to disorder is thus mathematical (N. N. Taleb and R. Douady Quant. Finance, in the press) and not derived from empirical data, as Shermer implies.

Shermer's suggestion that I should offer "a checklist of things companies or countries can do to prepare for black-swan events" overlooks 50 or so such heuristics based on the identification of convex responses.

Nassim N. Taleb Polytechnic Institute of New York University, New York, USA.

ntaleb@poly.edu

\section{CLARIFICATION}

The Correspondence headline 'Avoid constructing wind farms on peat' (J. Smith et al. Nature 489, 33; 2012) is misleading: it is developments on non-degraded, pristine peats that should be avoided. 